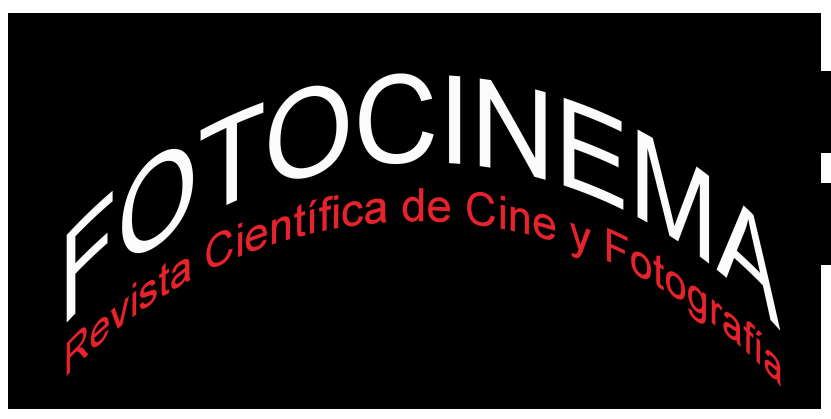

\title{
LA INSTANTÁNEA IMPOSIBLE: FOTOGRAFÍA, NEOVANGUARDIA Y POSMODERNIDAD EN EL CONTEXTO DEL ARTE CRÍTICO CONTEMPORÁNEO
}

\section{THE IMPOSSIBLE SNAPSHOT: PHOTOGRAPHY, NEO- AVANTGARDE AND POSTMODERNITY IN THE CONTEXT OF CONTEMPORARY CRITICAL ART}

\begin{abstract}
Resumen:
Las dificultades conceptuales que entraña la idea de posmodernidad en las prácticas fotográficas posteriores a 1970, no implican la inexistencia de un conjunto de actitudes icónicas que, vinculadas a la neovanguardia y a la consolidación de los estudios culturales y de género, mantienen un evidente diálogo con la tradición moderna. Más que plantear un repertorio de recetas visuales, la fotografía contemporánea, en tanto que momento inserto en la modernidad, articula una serie de discursos que, despojados de cualquier voluntad canónica, cuestionan el estatuto tradicional de la imagen $y$ el sentido que lo posmoderno posee. El presente artículo busca contextualizar dichas posiciones en relación a dos parámetros. En primer lugar, y desde una perspectiva teórica, toma algunas de las reflexiones de CartierBresson como paradigma de un pensar la fotografía que se contrapone a la voluntad político-ficcional y narrativa que se inicia con la crítica a la imposición lingüística tardo-moderna y a sus dictados formalistas. Por otro lado, el texto plantea la contextualización fotográfica en relación al desarrollo del arte contemporáneo y a su deriva antropológica, estableciendo una serie de características que toman como referencia visual el auge que en estas últimas décadas ha adquirido lo corporal como construcción cultural.
\end{abstract}

David Pérez

Universitat Politècnica de València, España davidperez@upv.es

\begin{abstract}
:
The conceptual difficulties with the idea of postmodernity in photographic practices after 1970 do not imply the non existence of a set of iconic attitudes which, linked to the neo-avantgarde and consolidation of cultural and gender studies, maintain an evident dialogue with modern tradition. Rather than propose a repertoire of visual recipes, contemporary photography, as a moment of modernity, articulates a series of discourses which, stripped of any canonical intention, question the traditional rules of image and meaning contained in the postmodern. This present article seeks to contextualise these positions in relation to two parameters. Firstly, and from a theoretical perspective, it takes CartierBresson's reflections as a paradigm for a philosophy of photography which runs counter to the political, fictional and narrative intention that begins with criticism of late modern linguistic imposition and its formalist dictates. Secondly, the text proposes photographic contextualisation in relation to the development of contemporary art and its anthropological drift, establishing a series of characteristics that take as visual reference the rise in recent decades of the body as a cultural construction.
\end{abstract}

Palabras clave:

Fotografía posmoderna; imagen; cuerpo; neovanguardia; estudios culturales.

Keywords:

Postmodern Photography; Image; Body; Neo-avantgarde; Cultural Studies. 


\section{Introducción y objetivos}

Dentro de la bibliografía publicada en castellano, Efecto real constituye uno de los textos más destacados destinado al estudio de las relaciones existentes entre fotografía y posmodernidad. El volumen, una antología editada en el año 2004 por el artista y también crítico Jorge Ribalta, agrupa un total de dieciséis ensayos que intentan abordar el sentido que poseen dichas relaciones, un sentido que, lógicamente, va a articularse desde la pluralidad de perspectivas que comportan los planteamientos concretos de los que parte cada texto. Ahora bien, el autor, con independencia de llevar a cabo en su estudio inicial la correspondiente justificación de los artículos que integran el libro - cuestión que requiere la presentación temática y el análisis secuencial de los mismos-, aprovecha la citada introducción para poner de relieve un hecho que dentro del presente contexto no puede pasarnos desapercibido ${ }^{1}$.

Aunque el título del libro conlleve una tácita alusión a la problemática posmoderna suscitada a partir de la confrontación entre los conceptos de imagen, simulacro, ficción, realidad y representación, alusión que también incide en la tensión, no menos posmoderna, detectada entre los ámbitos estético y ético - entendidas ambas realidades discursivas como espacios de interacción socio-política-; Efecto real posee un subtítulo -bastante explícito-, Debates posmodernos sobre fotografía, a través del que se constata $-\mathrm{y}$ no solo por lo que se enuncia, sino sobre todo por aquello que se elude - una doble controversia o, mejor aún, una doble precaución, en torno a la cual va a pivotar el desarrollo del volumen.

La primera de las cautelas a la que nos enfrenta Ribalta, encuentra su articulación en la desconfianza, nada disimulada, que este manifiesta hacia lo que podría ser considerado como "fotografía posmoderna”, una desconfianza que incide en la ambigüedad e, incluso, en las imprecisiones conceptuales

\footnotetext{
${ }^{1}$ Recordemos que la compilación llevada a cabo recoge, entre otras, aportaciones de artistas y teóricos, básicamente de procedencia anglo-norteamericana, que fueron publicadas en sus versiones originales desde mediados de los años 1970 a finales de la década de 1990. Entre los textos seleccionados destaca la presencia de Victor Burgin, Benjamin H. D. Buchloh, Jean-François Chevrier, Douglas Crimp, Rosalind Krauss, James Lingwood, Laura Mulvey, Craig Owens, Martha Rosler, Allan Sekula o Jo Spence.
} 
que un uso indiscriminado del término posmoderno - aplicado en este caso a un ámbito concreto de la actividad fotográfica de las últimas décadas- es capaz de generar. Las suspicacias y recelos que dan pie a esta situación derivadas fundamentalmente del sentido de superación temporal que se adhiere al prefijo pos-, prefijo que estaría delimitando el después de un algo periclitado y la consiguiente superación de un fenómeno previo- provocan, tal como veremos más adelante, una mayor susceptibilidad cuando dicho uso se incorpora a ámbitos relacionados con otras actividades artísticoarquitectónicas o, especialmente, cuando el mismo se circunscribe a la filosofía y al pensamiento contemporáneos.

Este hecho, con independencia del mayor o menor acierto argumental utilizado en su formulación, quedará más que patente en el carácter inacabado con el que algunos autores - pensemos, por ejemplo, en el caso paradigmático de Jürgen Habermas- definieron el proyecto moderno, un proyecto considerado como "incompleto" que, a pesar de haber perdido el ingenuo optimismo y la exultante confianza de sus primigenios postulados emancipadores, no por ello tenía que rechazarse ni dejar de estar sujeto a posibles y necesarias revisiones: "Creo - llegará a escribir Habermas- que en vez de abandonar la modernidad y su proyecto como una causa perdida, deberíamos aprender de los errores de esos programas extravagantes que han tratado de negar la modernidad" (Habermas, 1985, p. 32).

Ahora bien, junto a ello, el subtítulo utilizado por Ribalta también pone de relieve el carácter polémico y discutible -aunque, paralelamente, dinamizador y proactivo- que determinados planteamientos tildados de posmodernos han podido desempeñar en el debate artístico de los últimos años. Unos planteamientos que han actuado como foco de agitación y discusión destinados a resaltar el destacado papel que en la transformación de esa realidad artística han ejercido aquellas propuestas de índole neovanguardista que, situadas precisamente en el origen de ciertas actitudes posmodernas, han permanecido ajustadas a "la pretensión de un reingreso del arte en la praxis vital” (Bürger, 1987, p. 55), pretensión, no hay que 
olvidarlo, que en su momento no solo quedó auspiciada por la actitud posmoderna, sino por la propia modernidad, y ello, a través del programa que las vanguardias históricas intentaron desarrollar más allá del ámbito estrictamente plástico.

Conviene, por tanto, que reparemos con cierto detenimiento en ambas consideraciones, puesto que por medio de la fórmula utilizada, la elusiva referencia a lo posmoderno permite situarnos - por paradójica y ambivalente que resulte- en el espacio discursivo de una confrontación dialógica con lo moderno. Esta circunstancia, que cronológica e icónicamente toma como punto de inflexión un conjunto de prácticas -algunas fotográficas y otras no- surgidas a mediados de la década de 1970, va a propiciar que, desde un primer momento, nuestra atención pueda desplazarse desde el ámbito de la ontología al de la actividad. Un desplazamiento, sin duda alguna sugerente, que, planteado desde una perspectiva más amplia, lo que en verdad está proponiendo no es tanto la inclusión o no de una determinada realidad fotográfica en el interior de una taxonomía que, por comodidad y/o reduccionismo simplificador, etiquetamos como posmoderna, sino -y las cursivas son nuestras - la propia "redefinición del estatuto de la fotografía en el arte y la cultura modernos" (Ribalta, 2004, p. 23).

Estas dos premisas nos van a permitir profundizar en las próximas páginas en un aspecto que, retomado de Foucault en su relectura de la Aufklärung kantiana - la modernidad interpretada como disposición y postura-, puede sernos de utilidad no solo para situar ese espacio de actitudes del que se nutren las prácticas fotográficas posconceptuales, sino también para analizar sus aportaciones en relación a la evolución artística de esos mismos años. Teniendo en cuenta estas apreciaciones, deseamos entablar un diálogo -que no puede permanecer circunscrito a una irreductible contraposición de postulados estancos- entre el desarrollo de dichas prácticas protagonizadas por artistas como, por ejemplo, Sophie Calle, Rineke Dijkstra, Nan Goldin, Barbara Kruger, Sherrie Levine, Pierre et Gilles, 
Richard Prince, Martha Rosler, Cindy Sherman o Jeff Wall²- y la conceptualización de la imagen fotográfica llevada a cabo por autores de generaciones precedentes como Henri Cartier-Bresson, cuya elección en el presente artículo responde no tanto a su relación con posiciones paradigmáticas y/o canónicas del modernismo, como al interés metodológico que en relación a la teoría del arte venimos otorgando a las aportaciones procedentes de los textos de artista (Pérez, 2012), aportaciones que en el caso de este fotógrafo adquieren, dado el peso específico del personaje, una especial relevancia.

Establecidos estos objetivos, deseamos, a su vez, que el diálogo propuesto quede focalizado en dos aspectos que, dentro del discurso artístico contemporáneo, han asumido un particular relieve. Nos referimos, en primer lugar, al vinculado con el protagonismo escópico que el referente corporal ha adquirido como constructo cultural y campo de batalla - por utilizar la fórmula que Barbara Kruger empleó en 1989 en una de sus obras más conocidas, Your body is a battleground-. Paralelamente, dicho protagonismo podemos adscribirlo $-\mathrm{y}$ ello no con la finalidad de obtener una estricta explicación descriptiva, sino meramente contextual- a lo que algunos autores han calificado como el "giro" hacia un "paradigma etnográfico" (Foster, 2001, pp. 175-207), giro que ha deslizado el arte contemporáneo hacia discursos y ubicaciones transdisciplinares vinculados con la sociología, la antropología, el psicoanálisis, la crítica cultural e institucional, etc.

En segundo lugar, este diálogo también deseamos asociarlo a la importancia que este hecho conlleva en la recuperación narrativa de los microrrelatos contemporáneos - concebidos básicamente como discursos anti-metafísicos y anti-idealistas-. Esta recuperación consideramos que no solo contrasta, sino que también se alimenta de esa crisis de credibilidad - ya detectable, por otro lado, en Nietzsche y en su apelación a la genealogía- de lo que en su

\footnotetext{
${ }^{2}$ Como fácilmente puede deducirse, este listado en modo alguno intenta ser exhaustivo. Ello no es óbice para constatar un hecho incontrovertible en el panorama artístico posconceptual: el destacado papel que asume la presencia de la mujer y, en estrecha conexión con este fenómeno, el protagonismo alcanzado en el mismo por los discursos feministas.
} 
momento Jean-François Lyotard definió como grandes relatos o metarrelatos, esos mecanismos de legitimación que "simplificando al máximo" sitúan lo posmoderno en un espacio de incredulidad con respecto a cualquier discurso omniabarcante, de ahí que el "desuso del dispositivo metanarrativo de legitimación" al que impelen, haya quedado vinculado a "la crisis de la filosofía metafísica, y la de la institución universitaria que dependía de ella” (Lyotard, 1984, p. 10).

En función de este hecho, así como de la consiguiente pérdida de referencialidad atribuida a determinados discursos emancipadores, la fotografía de estas últimas décadas, al aspirar a una elocuencia concisa de certezas mínimas, centrará parte de sus esfuerzos en la recuperación del valor de lo íntimo. Y lo hará no por una necesidad idealista y/o narcisista de privacidad, sino por una decidida voluntad de transformación política, hecho que será, precisamente, el que podrá caracterizarla -aunque no sea de manera singular-. En este sentido, la apuesta por la inserción de lo considerado como privado dentro del ámbito social —inserción que estimula la hibridación entre lo personal y lo público - permitirá resituar el ámbito de lo político dentro del espacio de lo micropolítico3, un espacio que va a transformarse en eje de un fecundo diálogo entre lo estético y lo ético.

\section{Paradojas y contraprácticas en la imagen fotográfica de las últimas décadas}

Sin restar validez a la existencia de unas específicas maneras de ver, actuar y legitimar críticamente que surgen en torno a las décadas de 1970-1980, la posición adoptada por Jorge Ribalta se va a decantar, a la hora de cartografiar el panorama fotográfico surgido a partir de dichos años, por la

\footnotetext{
3 En relación a esta pérdida de referencialidad y a la paralela recuperación de lo privado como discurso micropolítico, el citado Lyotard señalará con posterioridad a la publicación de La condición postmoderna: "Esto no quiere decir que no haya relato que no pueda ser ya creíble. Por metarrelato o gran relato, entiendo precisamente las narraciones que tienen función legitimante o legitimatoria. Su decadencia no impide que existan millares de historias, pequeñas o no tan pequeñas, que continúen tramando el tejido de la vida cotidiana" (Lyotard, 1987, p. 31).
} 
reactualización de una expresión que había sido acuñada por Douglas Crimp, uno de los miembros más activos de la determinante e influyente October, revista que, desde su fundación a mediados de la década de 1970, ejerció un hondo impacto en la nueva teoría crítica norteamericana.

De este modo, Ribalta alude, no sin cierta aunque sutil ambivalencia, más que a un fotografía definida como posmoderna, a una "actividad fotográfica posmoderna”, hecho que a Crimp -en un texto publicado originalmente en la temprana fecha de 1980- le va a permitir situar a la fotografía, en tanto que práctica ausente y presente en el discurso histórico-artístico de la modernidad, como discurso protagonista de un "retorno de lo reprimido", noción que con posterioridad también será ampliamente utilizada por Hal Foster. "El discurso moderno - señala Crimp en "The Photographic Activity of Postmodernism"- creyó necesario reprimir el hecho innegable de que la fotografía había anulado el tribunal del arte, así que podemos decir con propiedad que la posmodernidad constituye el retorno de lo reprimido”. Un retorno que va a suponer la ruptura "con aquellas instituciones que son condición previa para el discurso moderno y lo forjan: en primer lugar, el museo; en segundo, la historia del arte, y finalmente [...] la fotografía” (Crimp, 2004, p. 150).

A través del circunloquio conceptual que parcialmente es recuperado por Ribalta - gesto, a su vez, que cabría relacionar con el momento reflexivo y de autoconfrontación que para Ulrich Beck define la actual etapa de la modernidad y la configuración de la sociedad posindustrial como sociedad del riesgo (Beck, 1996) - lo que la mencionada terminología suscita es, en verdad, una reflexión sobre el sentido de esas instituciones a las que acabamos de referirnos y, en especial, sobre cómo la "actividad fotográfica de la posmodernidad actúa [...] en complicidad con estas modalidades de la fotografía-como-arte [...] para subvertirlas y superarlas” (Crimp, 2004, p. 157). El objetivo que se persigue con esta estrategia intenta dar respuesta, desde lo que podemos considerar como perspectivas plurales, aunque no pluralistas, es decir, desde posiciones expandidas y básicamente 
antiformalistas, a una doble cuestión: ¿qué y cómo significar a través de la fotografía y de la propia actividad artística? Y, en paralelo a ello, ¿de qué modo desarrollar una actividad fotográfica que sea capaz en sí misma de incidir política y socialmente a través de la imagen?

Este interés antiformalista que no solo huye de la configuración lexicalizada de un repertorio estilístico, sino que se basa en una recuperación del discurso crítico en tanto que crítica del discurso, vincula de una manera directa, y no menos evidente, lo posmoderno y su acontecer con el propio hecho de lo moderno. Vinculación, a su vez, que ayuda a poner de relieve cómo la incidencia en lo político despierta el interés no únicamente por una imagen que se autodefina como política, sino también por un discurso que se ocupe de establecer una auténtica política de la imagen. De ahí que, tal como ya hemos sugerido con anterioridad, la voluntad artística por reconocerse en el hecho de lo político - y en el correspondiente decir de lo micropolíticosuscite su desplazamiento hacia la actividad y, por ello, hacia esa performatividad, tan influyente en el arte más reciente, que impulsa "la transformación de la obra de arte en acontecimiento" y, por tanto, en suceso y en transcurso destinado a cuestionar "las relaciones ligadas" a esa obra, es decir, las conexiones existentes entre "sujeto y objeto y [entre] los estatus material y sígnico" de la misma (Fischer-Lichte, 2011, p. 46).

Debido a ello, una parte destacada de la actividad fotográfica emprendida desde las décadas de 1970-1980 convertirá la imagen en un revulsivo y su discurso visual en centro de un devenir que actuará como crítica cultural y social, una crítica que, retomando de manera no idealista la sugerencia platónica de la anamnesis, luchará contra un determinado tipo de olvido -en este caso social y político-.

La imagen, en tanto que acción visual, va a ir dirigida, por consiguiente, a dotar de visibilidad a lo inadvertido, es decir, a mostrar aquello que genera opacidad dentro de una cultura de excesos escópicos en la que la depredación visual $-\mathrm{y}$ aquí la deuda posmoderna con los marxismos heterodoxos de Theodor W. Adorno y Guy Debord es más que palpable- se sustenta en la 
transformación del arte en industria cultural $-\mathrm{y}$, por ello, en forma de dominio- y en la voracidad y sobreabundancia mediáticas de lo espectacular. De este modo, convertida en mercancía de consumo -y en consumo de una mercancía - la actividad artística va a quedar sometida, en cualquiera de sus manifestaciones, a un proceso banalizador de desactivación estetizante contra el que la fotografía y el arte -a través de ese mencionado rechazo antiformalista - van a intentar posicionarse.

Desde esta perspectiva, la generalización e imposición canónica de determinados paradigmas modernistas de carácter estetizante, generará un proceso reduccionista en la concepción y en la hermenéutica del propio hecho artístico, un proceso -y parafraseamos aquí a Milan Kundera en la relectura que del mismo efectúa Zygmunt Bauman- tendente a hacernos olvidar que el sentido del arte, y también el de la imagen, no es otro que el de protegernos contra el olvido. Es decir, contra esa indiferencia -en modo alguno cauterizada a través de la mera mímesis documental de la memoriaque provoca no tanto el abandono de "lo sido", como el rechazo y devaluación del propio hecho de ser (Bauman, 2013, p. 96).

Ahora bien, aunque la pretendida elusión de una denominada fotografía posmoderna se asiente, en verdad, sobre una cierta ilusión o, mejor aún, sobre un paradójico deseo conceptual, Ribalta es consciente de que la "fórmula no deja de ser ambigua", hecho que en absoluto le impide expresar con claridad que todavía "más ambigua es la categoría de fotografía posmoderna, que intentaré no utilizar en la medida de lo posible" (Ribalta, 2004, p. 9). De este modo, resulta evidente que nos encontramos con una caracterización que puede parecer contradictoria o, incluso, extraña, pero en la que se detecta, de entrada, una situación incontrovertible: la redefinición o, si se prefiere, la reubicación de la imagen fotográfica dentro del espacio discursivo que se vincula a lo posmoderno y a su cartografía, debe ser tomada no desde la perspectiva que otorga el mero rechazo y/o la superación de lo moderno, sino desde otro planteamiento. Un planteamiento que podemos calificar - por utilizar expresiones de otro octoberiano como Hal Foster- "de 
oposición” y "de resistencia" y que, beligerante con lo que podría ser tomado como un "posmodernismo reaccionario" y de corte neoconservador, se basa en el desarrollo crítico de posiciones y estrategias que, tal como ya hemos apuntado, van a encontrarse vinculadas a la evolución de las propias vanguardias históricas -e, incluso, si se amplía el abanico histórico, a la formulación de ciertas actitudes que ya Charles Baudelaire había tematizado en sus aproximaciones al fenómeno del dandismo y a la nueva comprensión del presente- .

Esta idea de resistencia que Foster menciona actuará también como motor discursivo recurrente en uno de los textos más citados del momento. Nos referimos al ensayo que Fredric Jameson publica originalmente en 1984 en relación al posmodernismo y a la vinculación de este con el tardocapitalismo, texto en cuyas primeras páginas queda expuesta con claridad la implicación política que conlleva el hecho de lo posmoderno: "Toda posición posmodernista en el ámbito se la cultura -ya se trate de apologías o de estigmatizaciones- es, también y al mismo tiempo, necesariamente, una toma de postura implícita o explícitamente política sobre la naturaleza del capitalismo multinacional actual" (Jameson, 1991, p.14).

El reconocimiento de un posmodernismo crítico enfrentado a un posmodernismo abiertamente reaccionario quedará puesto de relieve por Foster en el volumen que dedicará al tema (1985)4. De manera directa este planteará con nitidez la necesidad y los límites del enfrentamiento: "Vemos, pues, que surge un posmodernismo de resistencia como una contrapráctica no solo de la cultura oficial del modernismo, sino también de la "falsa normatividad" de un posmodernismo reaccionario". Aceptar este hecho, conllevará a su vez tener que asumir que "un posmodernismo resistente se interesa por una deconstrucción crítica de la tradición, no por un pastiche

\footnotetext{
4 También en este caso nos encontramos con una recopilación de ensayos que, precedidos por una breve aportación de este autor, abordan desde la diversidad de su propia procedencia disciplinar - arte, literatura, arquitectura, estudios culturales, filosofía, antropología cultural...- el debate en torno a lo posmoderno. El libro, que con el paso del tiempo, se ha convertido en referencia ineludible, recoge textos de Jean Baudrillard, Douglas Crimp, Kenneth Frampton, Jürgen Habermas, Fredric Jameson, Rosalind Krauss, Craig Owens, Edward W. Said y Gregory L. Ulmer.
} 
instrumental de formas pop o pseudohistóricas". Como fácilmente puede observarse, las alusiones a la oficialización de una modernidad institucionalizada y, por tanto, estetizada, así como las referencias a deconstruir la misma críticamente, permiten poner de relieve el objetivo que el posmodernismo resistente desea alcanzar. Un objetivo que no va a suponer el retorno regresivo a unas pretendidas esencias -inmanentes $\mathrm{y}$ universalmente fijadas-, sino la puesta en marcha de una "crítica de los orígenes”, puesto que de lo que en último extremo se trata, según afirma Foster, es "de cuestionar más que de explorar códigos, explorarlos más que ocultar afiliaciones sociales y políticas" (Foster, 1985, pp. 11-12).

El concepto de contrapráctica al que acabamos de referirnos, encontrará en la noción de neovanguardia no su primera articulación, pero sí su primera recuperación tras la etapa protagonizada por las vanguardias históricas, hecho que va a permitir poner de relieve la importancia que asumirán en la evolución posterior de la fotografía las prácticas artísticas que, durante las décadas comprendidas entre 1950 y 1970, "buscaban alternativas al formalismo institucionalizado tardo-moderno" (Ribalta, 2004, p. 9), un formalismo que se relacionará, a nivel artístico-plástico, con las posiciones de Clement Greenberg y Michael Fried y con la consiguiente academización del expresionismo abstracto.

Ahora bien, con independencia de que esta formulación deba ser atribuida a Benjamin Buchloh, tal como sostiene Ribalta, o que la misma se remonte a la anticipación efectuada por Peter Bürger (Del Río, 2006, pp. 116-117), lo cierto es que la misma incide en el cuestionamiento anartistizante $\mathrm{y}$ contranormativo que va a caracterizar, siquiera sea parcialmente, tanto al neodadaísmo de Fluxus y al arte posconceptual, como a las derivas emprendidas dentro del ámbito del arte público, sociológico y de situación tras Mayo del 68 -y aquí somos conscientes de que estamos haciendo uso de una fecha carismática, acaso en exceso, con el riesgo que una simplificación de esta índole genera, dado que se podría llegar a efectuar una rápida y heterogénea identificación entre posmodernismo y sesentayochismo-. 
Lo apuntado hasta el momento permite constatar dos hechos. El primero de ellos nos ayuda a cuestionar la noción de posmodernidad en tanto que categoría histórica autónoma y/o paradigma teórico de transformación radical - aspecto sobre el que más adelante volveremos a insistir-. Este cuestionamiento remite a la inexistencia de una radical "ruptura epistemológica entre modernidad y posmodernidad" y a la consiguiente "continuación del proyecto moderno en un contexto tardo-capitalista" (Ribalta, 2004, pp. 19 y 23). La segunda premisa que hemos de tener presente alude al carácter impreciso que la utilización de este término posee en relación al discurso fotográfico contemporáneo, hecho que puede acarrear la conversión de una crítica a la estetización en una renovada estetización de la crítica.

\section{Pensar con la modernidad, actuar desde la posmodernidad}

Al margen del rastreo histórico que autores como Perry Anderson (2000, pp. 9-24) han efectuado sobre la presencia terminológica de lo posmoderno en fechas tan tempranas como las de 1934, relacionando esta primera aparición - no exenta de un sentido conservador- con el discurso crítico-literario de Federico de Onís; y al margen, asimismo, de que el término volviera a ser utilizado - ahora ya en el ámbito anglosajón- por el historiador Arnold Toynbee en 1954 al referirse en el octavo volumen de su dilatado y extenso $A$ Study of History a la existencia de una post-modern age que iba a quedar conceptualizada a partir del estallido del conflicto bélico mundial de 1914 -la primera guerra general posmoderna-; al margen de todo ello, insistimos, el recorrido efectuado por Anderson recala también - y es lo que ahora nos interesa destacar - en autores plenamente vinculados con la vanguardia artística posterior a la $2^{\mathrm{a}}$ Guerra Mundial. Nos referimos, entre otros, al poeta y escritor Charles Olson o al grupo de músicos, pintores y arquitectos relacionados con una experiencia tan singular como la representada en 
aquellos momentos por el Black Mountain College (John Cage, Robert Rauschenberg, Buckminster Fuller...5).

Esta necesaria referencia al fenómeno artístico en modo alguno resulta gratuita, ya que en numerosas ocasiones se ha tendido a reducir, no sin cierta imprecisión, lo posmoderno a dicho fenómeno. A pesar de ello, "sería erróneo considerar [la posmodernidad] como un acontecimiento exclusivamente cultural" (Jameson, 1991, p. 13), dado que "no es solamente un conjunto de formas estéticas sino también un paquete tecnológico" que ha propiciado la expansión y consolidación globalizada del "reino del espectáculo" (Anderson, 200o, p. 166). Con todo, hemos de señalar que el valor de esta interpretación multipolar -que conecta, por ejemplo, el discurso posmoderno con la realidad posindustrial y mediática, así como con la financiarización de la economía- no puede por sí mismo oscurecer el protagonismo que la actitud posmoderna ha asumido dentro del ámbito artístico-estético. Un protagonismo, sin embargo, que desde una perspectiva cualitativa, ha resultado más que ambivalente, puesto que al someterse a objetivos y estrategias estrictamente cuantitativos, el discurso artístico se ha visto obligado a conjugar, a través de su "vasta ampliación de la base social de la cultura moderna", el proceso de desleimiento y de "vulgarización cultural" contemporáneos -Anderson llega, incluso, a hablar de "plebeyización"-, con la consolidación paradójica de "una enorme disminución de su sustancia crítica", hecho que ha favorecido el fortalecimiento de una fórmula basada en la "insulsa pócima posmoderna" (Anderson, 2000, pp. 154-155).

En este sentido, se ha de tener en cuenta que la puesta en crisis de los referentes funcionalistas del estilo internacional dentro del ámbito de la

5 Cabe señalar que Olson será el último director del Black Mountain College, institución en la que precisamente el músico John Cage realizará durante 1952 -año en el que también se estrena su determinante 4' 33"- el primer happening del que se tiene noticia. Por otro lado, no hay que olvidar que la figura de Cage desempeñará un papel más que determinante en la prolongación de las ideas duchampianas dentro del ámbito artístico y en el consiguiente desarrollo y consolidación de Fluxus y la neovanguardia. Sobre esta consolidación, así como sobre las interacciones entre arte, música y neovanguardia puede consultarse el catálogo recientemente editado por el Centro José Guerrero de Granada con motivo de la exposición Música y acción (Sarmiento, 2012). 
arquitectura, o el propio cuestionamiento de la autorreferencialidad ensimismada y lexicalizada del expresionismo abstracto en la evolución de la pintura, constituirán puntos de partida recurrentes dentro de un discurso en el que la actividad artística no solo tendrá como objetivo los tópicos posmodernistas del pastiche citacional, la parodia banal o la parquetematización espectacularizada, sino también la utilización crítica del arte en tanto que instrumento dirigido a repensar "la pretendida "superación" del vanguardismo" y a replantear bajo "el pretexto de que es preciso volver a la comunicación con el público, el desprecio por la responsabilidad de resistir y de testimoniar, que las vanguardias asumieron durante un siglo" (Lyotard, 1987, p. 112).

De hecho, durante la década de los años 1970, los discursos de resonancias posmodernas procedentes de la teoría arquitectónica - pensemos, por ejemplo, en los casos de Robert Venturi, Denise Scott Brown o Charles Jencks- asumirán un destacado influjo en la configuración crítica del momento, un influjo sobre el que consideramos de interés detenernos brevemente. En relación a ello, cabe recordar que el propio Jencks situará el golpe de gracia otorgado a la arquitectura del movimiento moderno en una fecha y una hora muy concretas, el día 15 de julio de 1972 a las 15:32, instante en el que se producirá la voladura controlada del grupo de viviendas sociales Pruitt-Igoe situadas en Sant Louis, Missouri. Estas viviendas, realizadas por Minoru Yamasaki, autor, con posterioridad, de las ya también abatidas torres del World Trade Center, se convertirán en símbolo del fracaso modernista y del estilo internacional. Un símbolo que ponía de relieve el adocenamiento academicista de un tipo de arquitectura impersonal basada, entre otros aspectos, en la imposición transnacional de un modelo sustentado en el utilitarismo fagocitador del mercado.

En un breve texto en el que resumía su posición teórica, Jencks señalaba que la arquitectura mecanicista de la modernidad generaba lo que podemos definir como un hacer mudo: un hacer "que no dice nada", ya que opera "igual que una máquina reduccionista". El estilo internacional, por tanto, se 
va a mostrar incapaz de expresar "nada de la historia, nada de su contenido, nada de su experiencia, nada salvo el concepto de repetición”. Este autismo contextual que se halla complementado -en lo relativo al vocabulario formal utilizado - con un exceso de verbosidad y con una paralela sobreabundancia estructural, podría en algún caso y en ciertas particularidades muy concretas esconder "una cierta belleza”. Sin embargo, tampoco aquí llegará a alcanzar su objetivo, dado que "el aspecto más interesante a destacar" en este tipo de propuestas "es que el edificio parece aterrizado en su solar como un alienígena” (Jencks, 2004, p.14).

De este modo, la sensación de impostura léxica y de desprecio por el contexto semántico y sintáctico en el que la arquitectura se ubica -impostura, a su vez, que se apoya en un construir basado en la autoridad de la firma y en la falaz originalidad asociada a la misma - será sometida a una severa crítica en función de los nuevos parámetros que entran en juego. Debido a ello, lo original no dependerá ya de una mera operación de mercado, sino de un saber que reconozca el "volver a los orígenes" (Jencks, 2004, p. 27) y el consiguiente integrarse en el lugar, releyendo su idiosincrasia y reescribiendo su particularidad.

La crítica a la imposición modernista se asienta, por consiguiente, en la recuperación del emplazamiento y en el rechazo a la homogeneización del espacio $^{6}$. Una homogeneización que, al buscar la pretendida expresividad de una pureza formal, hallará su fundamentación en tres grandes pilares: en primer lugar, en la innovación dogmatizada; en segundo lugar, en la originalidad atribuida a la legitimidad de una autoría mediática y, en tercer y último lugar, en la abstracción desimbolizada que, sometida al ortodoxo pragmatismo de un aparente rigor funcional, transforma el espacio en un repertorio único y reiterado de estilemas convencionales. La conjunción de

${ }^{6}$ En relación a este último planteamiento, así como a la imposición universalizadora existente en el proceso de negación de las peculiaridades espaciales, destacan aportaciones como las realizadas Rem Koolhaas al aludir a los conceptos de generic city ["ciudad genérica"] (2006) y junkspace ["espacio basura"] (2007). Curiosamente, este último texto será publicado en su primera versión en la ya varias veces mencionada revista October, concretamente en su número 100, correspondiente al mes de junio de 2002. 
todo ello nos hace olvidar, precisamente - y valga el juego cacofónico-, que este hacer arquitectónico, es decir, este deshacer de la memoria, se sustenta en el olvido, hecho que vuelve a retrotraernos al ya mencionado sentido anamnésico del arte, aludido por Kundera, en tanto que actividad y proceso que, protegiéndonos del olvido y de la indiferencia, fortalece la memoria y, con ella, el valor de la diferencia.

Los autores que de una forma más contundente actuarán como paradigma de esta posición serán, sin duda alguna, los mencionados Robert Venturi, Denise Scott Brown y Steven Izenour, quienes en un texto provocador y en absoluto ambiguo, Learning from Las Vegas, volumen cuya primera versión inglesa definitiva vio la luz en 1977, resumieron, casi a modo de manifiesto, el descrédito de una modernidad que en el ámbito arquitectónico había proscrito el valor de lo simbólico, el sentido de la tradición iconológica y el poder comunicativo. De ahí, el interés retórico y persuasivo que, a nivel constructivo, los autores otorgarán no solo a la arquitectura vernácula primitiva y/o industrial, sino también a la arquitectura que incluye lo "vernáculo comercial" - y ello con la inevitable semanticidad publicitaria y la luminosa artificialidad rotulada que conlleva este tipo de práctica, entendida desde posiciones académico-modernistas como caótica, feísta o vulgar-.

Dicho interés, sin embargo, ayuda a poner de relieve dos hechos. Por un lado, la singularidad de un espacio urbano cuya fuerza radica no tanto en aquello que vehicula y representa - lo que podríamos considerar como su sentido ejemplar-, sino en lo que niega, es decir, en aquello que con su enunciación deja al margen. Ahora bien, por otro lado, el pretendido caos que este entorno articula, responde a una mirada no exenta de dogmatismo. La ciudad de Las Vegas no genera una incoherencia organizativa, "sino un nuevo orden espacial relacionado con el automóvil y la comunicación por autopista en una arquitectura que abandona la forma pura en favor de los medios mixtos". Esta hibridación provoca -y es lo que en este contexto más nos interesa poner de relieve- una autoconfrontación con nuestra manera de entender la realidad urbana, hecho que requiere un renovado utillaje 
conceptual: "El espacio de Las Vegas es tan diferente de esos dóciles espacios para los cuales se desarrollaron nuestras herramientas analíticas y conceptuales que necesitamos nuevos conceptos y teorías para abordarlo" (Venturi, Scott Brown \& Izenour, 1978, p. 102).

Desde esta perspectiva, si el hecho de poder aprender de Las Vegas es factible, se debe a que este entorno genera, tal como sucede en ámbitos como el artístico o el literario -y con independencia de sus aciertos o no-, "sus propias fuentes profanas y estilísticas”. Esta disposición trae consigo que Las Vegas pueda asumir el papel de una realidad constructiva dotada de un particular potencial educativo y didáctico, dado que la ciudad invita a través del simbolismo de su arquitectura no solo a ampliar y diversificar nuestra receptividad espacial, sino también a detectar las carencias narrativas y los acomodos conceptuales de nuestro discurso sobre lo urbano. En este sentido, "la alusión y el comentario, al pasado, al presente, a nuestros grandes lugares comunes o nuestros viejos clichés, y la inclusión de lo cotidiano en el entorno, sagrado y profano, es justamente lo que le falta a la arquitectura moderna de hoy" (Venturi et al, 1978, p. 97). Una arquitectura, no lo olvidemos, que se enfrenta al reto de tener que reformularse como espacio simbólico y realidad narrativa o, si se prefiere, como paisaje de impurezas y proceso de yuxtaposiciones.

Si nos hemos detenido en un ámbito como el arquitectónico se debe no únicamente a las teorizaciones que el hecho de lo posmoderno desarrolla en esta área, sino sobre todo a la actitud crítica que, en relación a una ortodoxia que anquilosa la lectura vanguardista, se impone en el panorama constructivo y urbanístico -y, por extensión, en el propio discurso artístico institucional - tras la finalización de la $2^{\mathrm{a}}$ Guerra Mundial. De este modo - y volvemos de nuevo a lo señalado con anterioridad al referirnos a las imprecisiones que podía generar un taxonomía como la vinculada al concepto de fotografía posmoderna-, lo que se perfila en este panorama no es la conversión de lo moderno en anatema y, por ello, la instauración de un nuevo catecismo basado en el rechazo modernista, sino la revisión crítica de 
un proceder que, sustentado en la transformación de la autonomía y autorreflexividad plásticas, deviene discurso transitivo de interdependencias e imbricaciones. Un discurso de coimplicaciones críticas que no solo va a afectar al hecho arquitectónico y urbanístico, sino que, tal como venimos señalando, también se constata en la teoría artística a través de las críticas antiformalistas operadas sobre el apostolado greenbergiano.

$\mathrm{Al}$ respecto, resulta interesante observar cómo, incluso los propios autores de Learning from Las Vegas, efectúan, coincidiendo con la publicación esta obra, una serie reflexiones que, siquiera sea en parte, refuerzan lo que venimos apuntando. Así, en el prólogo redactado para la primera edición de este volumen podemos leer: "Como hemos criticado la arquitectura moderna, cumple declarar aquí nuestra intensa admiración por su primer período, cuando sus fundadores, sensibles a su tiempo, proclamaron la revolución correcta”. Este reconocimiento, a su vez, se ve complementado por una doble apreciación. Por un lado, la argumentación crítica desarrollada desea referirse "principalmente a la prolongación distorsionada e irrelevante de esa revolución hoy vieja”. Junto a ello, dicha crítica no busca asumir un carácter único, ya que "cuantas más direcciones tome la arquitectura en este punto, mucho mejor" (Venturi et al, 1978, p. 14).

Si bien es cierto que la revolución vinculada a la modernidad puede ser considerada hoy en día como un hecho histórico -dado que social y culturalmente se halló inmersa en un contexto preciso-, no menos cierto es que las principales críticas con las que nos encontramos, tanto las formuladas por estos como por otros autores, no van a ir dirigidas contra el sentido de esa revolución, sino contra la imposición ahistórica de un conjunto de normas canónicas y formulismos lexicalizados que, en su reiteración, quedan semánticamente desactivados y, por ello, despojados de cualquier sentido transformador. El problema, por tanto, no radica en la preservación de una actitud -ética y estética一, sino en la prolongación cosmética e inoperante de un hacer reducido a pauta estilística y a norma estandarizada. 
En función de este hecho, es decir, en función del valor que otorgamos a esta persistencia actitudinal que es la que se vincula con ese ya citado posmodernismo de resistencia que, huyendo de posiciones "apocalípticas", plantea no tanto "rupturas netas", como "desarrollos desiguales" (Foster, 1985, p. 11), resulta evidente que cualquier análisis conceptual que tenga que efectuarse sobre el mismo, ha de apoyarse en una relación dialógica con los enunciados modernos y tardomodernos, relación que en cierto modo tiene que problematizar la propia noción de historia y la de sus categorías.

Debido a ello, puede resultarnos de interés retomar, siquiera sea de forma parcial, la lectura foucaultiana en torno a la noción de Ilustración y, en concreto, sustentar esta aproximación en una de las tres revisiones que el pensador francés dedica, entre 1978 y 1983, al conocido texto, Was ist Aufklärung?, publicado por Kant en 1784. En este sentido, cabe destacar que en la última de estas revisiones, una conferencia impartida en Berkeley durante el otoño de 1983, Foucault incide de manera muy precisa en el rechazo a una interpretación historicista de la Ilustración, es decir, en la refutación de una lectura que tome en consideración el acontecer de lo ilustrado como periodo o suceso que responde a una acotación temporal.

Aunque el autor de Las palabras y las cosas reconozca que es frecuente la utilización de la idea de modernidad concibiéndola como una época o, incluso, como "un conjunto de rasgos característicos de una época”, hecho que permite establecer una cronología delimitada por una "más o menos ingenua o arcaica" premodernidad y "una enigmática e inquietante" posmodernidad, ello no le impide poner en duda dicha linealidad históricotaxonómica. Al respecto, señala Foucault: "Teniendo como referencia el texto de Kant, me pregunto si no se puede considerar la modernidad como una actitud más que como un periodo de la historia”. La pregunta va encaminada, por tanto, a dotar a la modernidad de un sentido históricamente transversal que pueda posibilitar su dinamización crítica, un sentido en el que la noción de actitud requiere ser redefinida en tanto que disposición, es decir, en tanto 
que "elección voluntaria" y "modo de relación con respecto a la actualidad" (Foucault, 2003, p. 81).

Al quedar desligada de una posición historicista, la modernidad se desustantiviza y se transforma en acción, es decir, en hecho verbal que solo puede conjugarse desde el presente, ya que lo que la misma establece es una relación - un imprescindible diálogo- con lo actual. Desde esta perspectiva, se configura como "una manera de pensar y de sentir, una manera también de actuar y de conducirse que, simultáneamente, marca una pertenencia y se presenta como una tarea" (Foucault, 2003, p. 81). Lo fundamental, por tanto, ya no radica en marcar un principio y un final - un origen y una superación-, sino en reconocer el sentido de esa tarea y situar la misma en el marco de una actuación, es decir, en relación con un comportamiento y, por ello, en conexión con una ética.

La actitud de la modernidad, consiguientemente, se prolonga en el decir crítico de la posmodernidad, dado que lo planteado es "el alto valor del presente" y la "obstinación en imaginarlo de otra manera y en transformarlo" (Foucault, 2003, p. 85). En tanto que actividad crítica y fenómeno performático, es decir, en tanto que trabajo consciente sobre el propio yo, lo posmoderno revela una "labor paciente" no solo destinada a dar "forma a la impaciencia de la libertad”, sino también a generar una actitud de evaluación, "en la que la crítica de lo que somos es a la vez análisis histórico de los límites que nos son impuestos”, un hecho que, sin duda alguna, prueba la posibilidad de su transgresión (Foucault, 2003, p. 97).

Si tenemos en cuenta la lectura foucaultiana y, a su vez, obviamos la consideración de este autor como integrante de lo que algunos definieron como "jóvenes conservadores" (Habermas, 1985, p. 34), podemos dotar de un adecuado marco conceptual a esa parte de la producción fotográfica posterior a las décadas de 1970-1980 que nos ocupa. En este sentido, cobra un renovado valor el hecho de que, pese a que la fotografía pueda ser considerada como "el medio artístico central para la actividad posmoderna" y de que, incluso, parafraseando a Craig Owens, sea factible afirmar que "el 
debate posmoderno fue un debate sobre la fotografía" (Ribalta, 2004, p. 15), a pesar de ello, repetimos, conviene no olvidar que el desarrollo de este tipo de prácticas y experimentaciones no puede desgajarse de un discurso que, si bien había quedado proscrito en los dictados formalistas, no por ello se encontraba ausente en otro tipo de planteamientos. Al respecto, resulta conveniente recordar cómo algunas de las temáticas centrales desarrolladas en las últimas décadas, recogen reflexiones en torno a cuestiones básicas de la vanguardia. Nos referimos, por ejemplo, a la recuperación del discurso ético y a su vinculación con la actividad estética, al restablecimiento del sentido político en el hecho artístico, a la crítica a la noción de sujeto e identidad, al uso conceptual de la imagen, a la reinserción de la actividad artística en la realidad vital, etc.

Ahora bien, ¿̇significa lo señalado que estemos negando especificidad a las prácticas emprendidas en el ámbito fotográfico durante el periodo que nos ocupa? Responder a esta pregunta conlleva situar, siquiera sea de forma un tanto simplificadora, el decir de lo posmoderno dentro del discurso fotográfico predominante en el momento de su aparición. A través de este gesto, sin embargo, no deseamos ni efectuar una tipificación reductora de la situación, ni en menor medida delimitar unos paradigmas conceptuales que actúen como modelos discursivos de contraposición. El objetivo, por el contrario, es otro: se trata de bosquejar las posibilidades de un diálogo que, partiendo de una de las voces más representativas de un determinado modo de hacer considerado como canónico - nos referimos al de Cartier-Bresson-, permita establecer nuevos puntos de conexión e interrelación dentro del panorama fotográfico contemporáneo. $\mathrm{Al}$ respecto, no hemos de olvidar que cualquier diálogo con un determinado pasado, no supone la mera recuperación del mismo, sino su inevitable reescritura. Ello hace que leamos el pasado al escribir nuestro ahora y que dicho pasado pueda ser leído tan solo como problematización, es decir, como análisis destinado a poner de relieve la paradójica genealogía que subyace en el uso posmoderno de la imagen. 


\section{Relatar sin instantes: la construcción de lo decisivo}

Algunos de los conceptos más utilizados por Cartier-Bresson a la hora de referirse a su propio trabajo fotográfico, un trabajo que el autor no considera en sentido estricto como tal, puesto que si "una cosa es segura" es que "la fotografía no es un trabajo", sino la "entrega a un "duro placer"” (CartierBresson, 2014, p. 82), pueden resultarnos de gran interés de cara a configurar la genealogía a la que aludíamos, dado que los mismos apelan de manera constante y recurrente a un conjunto de ideas - como las de instinto, inmediatez, autenticidad, intuición, testimonio, realidad, temporalidad...de hondo calado en la tradición de la teoría fotográfica. Esta circunstancia permite poner de relieve el interés por un hacer fotográfico en el que lo que importa es, ante todo, el respeto por una realidad - fija y aprehensible- que parece hallarse plenamente establecida $y$, ante la cual, el fotógrafo, transformado en notario privilegiado de la misma, ha de "ser tan invisible como sea posible”, de ahí que no deba ““"preparar” nada, [ni] “arreglar” nada, sencillamente estar ahí” (Cartier-Bresson, 2014, p. 10)—.

Esta sumisión a una realidad que, transparente y carente de códigos, existe más allá de la intervención y/o de la relación del sujeto con la misma, se articula en torno a un discurso icónico - también transparente y obvio en su inmediatez interpretativa- que encuentra su más adecuada formulación en la "poética del instante", una poética ante la que la fotografía no puede más que rendirse. $\mathrm{Y}$ ello es así en tanto que la imagen fotográfica es concebida como un ejercicio de automatismos sustentados en la intuición y el impulso: "La fotografía no se calcula, no tiene nada de intelectual. No vas con una intuición explícita, tienes una intuición y más tarde decides si eso se tiene en pie o no" (Cartier-Bresson, 2014, p. 82).

Partir de estos supuestos conlleva dotar a la fotografía de un carácter sustancialmente testimonial. Un carácter que, tomando la imagen como realidad documental, se basa en la apreciación de lo efímero y en la consiguiente lucha que esta "batalla constante con el tiempo" supone, 
especialmente si el objetivo de la misma va encaminado a "captar lo inmediato [y] el gesto fugaz". Ahora bien, junto a ello, esta captación de la instantaneidad solo adquiere su verdadero sentido cuando es llevada a cabo de manera mecánica y sin intervención consciente, es decir, cuando pensar y actuar se supeditan a la mirada -o sea, "jamás mientras se fotografía" (Cartier-Bresson, 2014, p. 36)-. En este sentido, la fórmula bressoniana del "instante decisivo", acuñada en un texto elaborado en 19527, va a circunscribir lo fotográfico a un registro testimonial y "sigiloso" por "fijar" una realidad que viene dada y que no puede quedar manipulada "ni durante la toma, ni en el laboratorio" (Cartier-Bresson, 2003, p. 19).

Aun a riesgo de haber simplificado en exceso la postura bressoniana, lo señalado aclara, siquiera sea en parte, el hecho de por qué la fotografía -en tanto que práctica artística e inapelable ejercicio mimético-, va a convertirse en la protagonista involuntaria de un permanente recelo por parte de todas aquellas otras actividades artísticas vinculadas con la modernidad. Una cuestión, la de esta inveterada desconfianza, que encontrará su explicación más pertinente en la relación que la imagen fotográfica analógica mantendrá con lo que Roland Barthes definió, en uno de sus textos más conocidos, La chambre claire (1980), como el noema de la fotografía y su bifronte discurso, un discurso destinado a reflexionar no solo sobre el "esto ha sido", sino también sobre el hecho de que "la cosa haya estado allí", apreciación dual que invita a pensar en torno a la presencia de lo que ya no es, así como sobre aquello que se nos dice que ha sido.

Ahora bien, la constatación de estas suspicacias en relación al hecho fotográfico va a verse modificada con la aceptación, sin duda alguna paradójica, de la fotografía - y de los valores testimoniales tradicionalmente implícitos a la misma- dentro de un contexto artístico comprometido con la

\footnotetext{
7 En diversas ocasiones Cartier-Bresson ha hecho referencia al origen de esta fórmula que retoma del cardenal de Retz y que utiliza como cita introductoria para el texto "El instante decisivo", integrado en Images à la sauvette. El citado cardenal había escrito: "No hay nada en este mundo que no tenga un momento decisivo" y el fotógrafo, partiendo de ello, comenta: "De todos los medios de expresión, la fotografía es el único que fija el instante preciso" (Cartier-Bresson, 2003, p. 19).
} 
crítica a los postulados modernistas. En este sentido, el descrédito visual e icónico que alimentó a importantes sectores de la neovanguardia, incluidos el arte conceptual de naturaleza más lingüístico-analítica y la actividad performática vinculada al body-art, generará la paradoja de que la mayoría de obras que quedaron cobijadas bajo tales denominaciones tuvieran que apoyarse para su difusión en el propio registro fotográfico. Un registro que asumirá - aunque ahora redimidos y exentos de cualquier crítica- conceptos como los de objetividad, inmediatez o autenticidad, todos ellos tan próximos, por otro lado, a los esgrimidos por Cartier-Bresson.

De este modo, la fotografía quedó transformada, según apuntó John Roberts, en "el medio por el cual la salida del arte conceptual del recinto modernista se hacía realizable como práctica". Este hecho, sin embargo, no impidió que la fotografía fuera per se de muy “escaso interés para la mayoría de los artistas conceptuales, lo cual [produjo] una situación en la que la intermediación crítica se [otorgó] a la imagen fotográfica sin que la fotografía se [convirtiera] en un medio teóricamente consciente de sí mismo” (Roberts, 2009, pp. 26-27).

Aunque aceptemos el reduccionismo en el que podemos caer, parece evidente que el arte de finales de la década de 1960 y comienzos de los años 1970 puso de relieve el valor de la producción artística no solo como actividad básicamente reflexiva -recogiendo, así, la herencia anti-retiniana duchampiana-, sino también como actividad de carácter decididamente político - pensemos, por ejemplo, en Hans Haacke y su conocida obra Shapolsky et al. Manhattan Real Estate Holdings: A real-Time Social System, as of May, 1, 1971-. El citado Roberts sintetizará de manera precisa la naturaleza de la situación generada. En primer lugar, este hecho implicará "desplazar la función principal del artista como productor de objetos discretos a productor de ideas sobre otras ideas” y, en segundo lugar, entrañará también tener que "separar el arte de las suposiciones previas sobre lo que es el arte” (Roberts, 2009, pp. 28-29). La unión de ambas circunstancias dotará de un nuevo sentido a la actividad fotográfica, ya que la 
misma se alejará tanto de los preciosismos esteticistas de la modernidad académica, como de su correspondiente institucionalización museística recordemos, al respecto, el papel desempeñado por John Szarkowski como director del Departamento de Fotografía del MoMA en la década de los años 1960-.

Este rechazo de las posiciones formalistas suscitará, sin embargo, una ambivalente situación, ya que la fotografía asumirá un prestigio como práctica no sospechosa, no por ser considerada como un instrumento de transformación artística y/o de reflexión política sobre la imagen, sino por su fidelidad a lo documental y al sentido anti-expresivo que se asocia a su pretendida objetividad, es decir, por "cuestionar el concepto de habilidad artística consagrado en las interpretaciones modernista y tradicional de gusto y sensibilidad" (Roberts, 2009, p. 39). Dicha fidelidad, a su vez, conllevará una aceptación de lo fotográfico como simple registro impersonal y dispositivo de copia meramente indicial - de hecho, un artista conceptual del relieve de Douglas Huebler llegará a definir a la cámara como "herramienta tonta”-, un registro cuyos resultados, según recogerá Liz Kotz, no solo se "distancian de los modos convencionales de autoexpresión", sino que también "imitan e incluso fetichizan las formas visuales y lingüísticas de la cultura tecnocientífica" (Kotz, 2009, pp. 57 y 63).

Sin embargo -y es lo que en el presente contexto llama poderosamente la atención-, el uso de la fotografía, aun partiendo de estos supuestos e implicaciones, acarreará una generalización de su presencia y, por ello, una aceptación de su uso dentro del ámbito artístico de la neovanguardia, hecho que cobrará un especial significado en autores relacionados con el land art - como Robert Smithson o Nancy Holt- o con artistas que trabajarán en contacto directo con el medio natural en cualquiera de sus dimensiones - pensemos en artistas como Christo, Richard Long o Hamish Fulton-.

De este modo, aunque la fotografía fuera utilizada en estos ámbitos críticos con el formalismo academicista de manera estrictamente instrumental, no menos cierto es que autores como, por ejemplo, Victor Burgin, Allan Sekula o 
Martha Rossler comenzarán a desarrollar un trabajo destinado a cuestionar la propia naturaleza del hecho fotográfico y, por tanto, a resituar a la fotografía dentro de un tipo de prácticas centradas en el análisis de la cultura de la imagen y en la especificidad que el acto fotográfico posee, una especificidad que hará posible a algunos autores abordar más que los problemas inherentes a la imagen, el propio hecho de la imagen como problema y, por ello, a plantear, parafraseando a Benjamin Buloch, el desplazamiento "desde algo similar a una "estética del índice" a una explícita "política de la representación”" (Kotz, 2009, p. 82), giro, añadimos nosotros, que supondrá el reconocimiento de lo estético, como discurso ético.

Este hecho, cuya influencia en la fotografía de resonancias posmodernas será fundamental, posibilitará la apertura de lo fotográfico -a través del autocuestionamiento y de la crítica que la modernidad efectúa sobre sus propios lenguajes y códigos- a reflexionar sobre sus límites, tarea que, curiosamente, será llevada a cabo no por los fotógrafos o fotógrafas vinculados al modernismo institucionalizado, sino por artistas plásticos que se hallarán totalmente alejados de los imperativos lexicalizados construidos por Steichen en The Family of Man o por el ya mencionado Szarkowski desde el MoMA neoyorquino.

Las consecuencias que provocará esta apertura, es decir, las derivas que acompañarán a este desplazamiento no se harán esperar. De ahí que "la aparición de una fotografía reflexiva, a partir de las estrategias iconofóbicas del conceptualismo analítico, [hará] posible producir un arte representacional que [evitará] muchos de los problemas de la iconofilia" (Roberts, 2009, p. 54). Este retorno a lo representativo, sin embargo, no supondrá un giro pre-moderno ni una asunción tardo-moderna. Lo que el mismo conllevará será una recuperación de la imagen como realidad textual y, a su vez $-\mathrm{y}$ aquí el influjo feminista y de los discursos de género será fundamental - un restablecimiento de esa realidad textual y narrativa como hecho político y cultural, es decir, como acto que desde el ámbito del microrrelato -concebido como discurso de reivindicación de la 
micropolítica - perfila el descrédito crítico del metarrelato, un descrédito que se vertebra partiendo de estrategias concretas como la performatividad (Hannah Wilke), la teatralización (Cindy Sherman), la elaboración escenificada (Jeff Wall), la reconstrucción biográfica (Nan Goldin), la cita pictoricista (Joel-Peter Witkin), el simulacro (Sherrie Levine), la reelaboración simbólica (Pierre et Gilles), la ironía (Duane Michals), la reivindicación de lo personal como político (Jo Spence), la equiparación entre lo público y lo privado (Barbara Kruger), etc.

De este modo, frente al "yo no busco demostrar" que es formulado cuando se considera que "la fotografía no demuestra nada de nada" (Cartier-Bresson, 2014, p. 110), vamos a encontrarnos con un hacer fotográfico que, interesado por la producción social del significado, va a utilizar la imagen como elemento mostrativo de la propia construcción ideológica que subyace en la mirada, construcción que va poner de relieve el carácter codificado que presenta cualquier actividad humana -entendida como discurso y cuerpo textual-.

\section{De cuerpo presente (un apunte tangencial de carácter antropológico)}

A raíz de este interés por la construcción ideológica y política que entraña cualquier práctica social, durante estos años asumirá un particular relieve -y no solo dentro del ámbito artístico, sino especialmente en el fotográficola presencia corporal concebida como fisicidad de lo textual y textualidad de lo físico. Es decir, como realidad de incertidumbres que con certera destreza social quedan construidas. Partiendo de ello -y del giro etnográfico que esta actitud propicia-, deseamos plantear en este último apartado dicha temática para, así, trasladar la interpretación de esta realidad a la propia realidad fotográfica del periodo que estamos abordando, hecho que puede resultar revelador del sentido que asume la imagen en este contexto.

$\mathrm{Al}$ respecto, cabe señalar que el cuerpo que la fotografía cuestiona a partir de los años 1970-1980 no surge como algo cerrado ni definitivamente dado, sino 
como proyecto que se realiza y elabora. De este modo, lo corporal queda analizado como espacio de una tensión que adquiere forma y configuración en función de un discurso, de ahí que sea tomado como signo y escritura como texto y trazado intertextual- y de ahí, también, que lo semántico se superponga a lo antropológico. Esta superposición nos permite incidir en un hecho: el cuerpo fotografiado en clave posmoderna no es físico en el sentido que dictan la genética o sociobiología, sino que lo es en tanto que escritura de escrituras. O sea, en tanto que discurso transversal - “cuerpo racial”, “cuerpo físico", "cuerpo colectivo" (Pultz, 2003, p. 114)— que responde a supuestos implícitos generizados.

La fotografía nos muestra que hablamos del cuerpo, pero lo hacemos porque somos cuerpo. De ahí que reconocernos como espacios de corporalidad no conlleve estar tomando como legítimo el hecho de que podamos decir que habitamos en esos espacios: no podemos habitar los espacios del cuerpo, puesto que no vivimos en un cuerpo, sino que vivimos corporalmente. Desde esta perspectiva, no hay que olvidar que resulta contradictorio señalar que poseemos un cuerpo o que el nuestro es un cuerpo unitario. Lo corporal, en este sentido, no pertenece al discurso del tener ni del disponer, sino a un ámbito más resbaladizo y fluctuante que es el de lo impropio, es decir, el de un ámbito carente de propiedad. Ello hace que la fotografía no refleje ni represente cuerpos, sino que los genere, ya que toda mirada surge como fruto de un discurso y, por tanto, como ejercicio cultural.

La fotografía, por tanto, va a atacar la limpieza plástica en la que se sustentaba el eje de una pureza formal que, apoyada en la rigurosa búsqueda de una autonomía artística, terminaba por convertirse en receta ensimismada y autosuficiente. A su vez, la misma contravendrá también los cánones impuestos desde la hiperrealidad publicitaria. Al respecto, autoras como Orlan llevarán a cabo una crítica a esos cánones partiendo de la transformación de su propio cuerpo en una obra procesual destinada a permanecer inacabada en el permanente cuestionamiento de la reificación a la que la corporalidad está siendo sometida. 
Ello determinará una nueva y atormentada sensibilidad dentro del ámbito artístico. El dolor, el abatimiento y la desesperanza generarán una iconografía en la que un cierto erotismo - pensemos, por ejemplo, en casos como los de Tracey Moffat o Jeanne Dunning- empujará no tanto al goce, como a la perplejidad y al cuestionamiento. Al igual que al finalizar la $2^{\mathrm{a}}$ Guerra Mundial el cuerpo solo podía latir desde la herida y el desgarro, en los años finales del siglo XX y comienzos del XXI el mismo solo podrá articularse transgresoramente desde la incomprensibilidad, la contradicción y la desolación.

De este modo, la fotografía asociada al discurso posmoderno nos ofrece un decir crepuscular en el que la corporalidad deviene texto de un naufragio y certeza de una perplejidad (Pérez, 2004). Una perplejidad que adquiere sentido como envoltura y sombra, es decir, como producto que se sabe envase y como impostura que se reconoce pantalla. Ello hace que la propia fisicidad vaya paulatinamente desvaneciéndose, adquiriendo su máxima presencia en la descorporeización que acompaña a la materialidad mediática, una materialidad que sólo se hace desde el señuelo digital. La fotografía actual nos muestra, en definitiva, los despojos de un cuerpo que sólo refulge en la sombra. Un cuerpo, sin embargo, que reclama volver a ser vivido. Como también sucede con algunas de las ideas - todavía no olvidadas- de la modernidad.

\section{Conclusiones}

El recorrido que hemos efectuado en relación a las prácticas fotográficas llevadas a cabo tras la eclosión de las corrientes conceptuales y sus derivas feministas - hecho que se desarrolla y consolida a partir de la década de los años 1970-, ha intentado poner de relieve el carácter contradictorio que posee la utilización categorial de la noción de posmodernidad. Si bien es cierto que la actividad artística, tomada en su sentido más expandido - es decir, definida no solo desde perspectivas plásticas, sino también cinematográficas o arquitectónicas-, presenta durante dichos años una serie 
de características específicas que, asimismo, pueden rastrearse en áreas tan diversas como la filosofía, la sociología o la literatura; hemos de tener en cuenta que dicha especificidad debe ser analizada con ciertas precauciones. Incluso en un ámbito como el artístico, en el que el término ha gozado de un extendido predicamento, no se debe olvidar el hecho de que la actividad generada ha presentado no tanto una ruptura, como una continuidad con las prácticas neovanguardistas emprendidas durante la década de los años 1960. Dicha continuidad resulta especialmente significativa en lo concerniente a la recuperación crítica del carácter político y social del discurso estético, algo de lo que la modernidad institucionalizada y/o lexicalizada había abjurado, dada su apuesta formalista por la autonomía del lenguaje artístico y el consiguiente abandono del carácter ético que la vanguardia histórica de comienzos del siglo XX había teorizado.

Incidir en esta cuestión nos ha servido para remarcar no tanto la posible legitimidad conceptual del discurso posmoderno, como para cuestionar el reduccionismo al que la noción de modernidad se ha visto sometida desde parámetros institucionales. Frente a la idea de una estetización vacua del hecho artístico, la fotografía del periodo nos ha mostrado la problematicidad implícita a cualquier construcción cultural, ya esté afectando la misma al espacio icónico, al corporal o a cualquier otra realidad textual. De este modo, una de las principales aportaciones que encontramos en las obras generadas en estos años radica en la recuperación de evidencias que nos proponen, una recuperación que supone, tal como Edgar Allan Poe puso de relieve en uno de sus más conocidos relatos, hacernos ver que lo visible no siempre resulta manifiesto. Si en la narración del escritor norteamericano una carta de gran valor pasaba desapercibida al hallarse a la vista de cualquiera, en nuestro caso lo escamoteado por el modernismo institucionalizado ha sido algo tan difícilmente cuestionable como el sentido político de la imagen y su paralela -así como necesaria- política de los sentidos.

Redescubrir el valor de este sentido permite cuestionar la idea de superación que implícitamente conlleva un término como el de posmodernidad. Desde 
esta perspectiva, lo posmoderno estaría actuando no como rechazo y/o rebasamiento de lo moderno, sino como relectura de esa modernidad, es decir, como mirada crítica que, auspiciada por el proceder de la reflexividad y autoconfrontación señalado por Beck, reescribe el carácter ingenuo del proyecto emancipador moderno. Constatar esta ingenuidad, sin embargo, no debe hacernos perder de vista una cuestión: la fotografía posterior a las décadas de 1970-1980, al redefinir el estatuto de la imagen dentro de una cultura que desde Guy Debord tan solo es espectáculo, sustenta una gran parte de su actividad en la reutilización política del discurso icónico. Debido a ello, la crisis de los grandes relatos y de su corolario de legitimaciones omniabarcantes, dará pie a una resemantización de lo político dentro del ámbito de lo micropolítico, ese espacio desterritorializado que Gilles Deleuze vinculará a la resistencia contra el poder originada en lo menor y en lo minoritario. Una resistencia que, al permanecer situada fuera del marco de lo macropolítico, transforma lo cotidiano en un espacio en el que lo privado y lo personal devienen discurso público y social.

Por su parte, la resemantización a la que acabamos de aludir, contará con un activo instrumental teórico impulsado desde la revista October, un instrumental que, centrado en la crítica antiformalista, buscará redefinir el sentido de la imagen y de la fotografía en tanto que relato transversal y antiestetizante. A través de todo ello se buscará, por un lado, potenciar la performatividad ficcional del discurso fotográfico, uniéndola a la crítica cultural y de género; $y$, por otro, impulsar la resistencia política inherente a las contraprácticas artísticas, unas contraprácticas que, en su rechazo a la ahistoricidad y al discurso cosmético del formalismo, no solo desean quedar circunscritas a ámbitos culturales, sino reescribirse dialógicamente desde y con cualquier discurso procedente de otras áreas del conocimiento.

\section{Referencias bibliográficas}

Anderson, P. (2000), Los orígenes de la posmodernidad. Barcelona: Anagrama. 
Bauman, Z. (2013). La cultura en el mundo de la modernidad líquida. Madrid: Fondo de Cultura Económica de España.

Beck, U. (1996). Teoría de la sociedad del riesgo. En Beriain, J. (Comp.). Las consecuencias perversas de la modernidad (pp. 201-222). Barcelona: Anthropos.

Bürger, P. (1987). Teoría de la vanguardia. Barcelona: Península.

Cartier-Bresson, H. (2003). Fotografiar del natural. Barcelona: Gustavo Gili.

Cartier-Bresson, H. (2014). Ver es un todo. Entrevistas y conversaciones 1951-1998. Barcelona: Gustavo Gili.

Crimp, D. (2004). La actividad fotográfica de la posmodernidad. En Ribalta, J. (Ed.). Efecto real. Debates posmodernos sobre fotografía (pp. 150162). Barcelona: Gustavo Gili.

Del Río, V. (2006) El concepto de neovanguardia en el origen de las teorías del arte postmoderno. En Hernández Sánchez, D., Notario Ruiz, A., Pinto, J. M., Piñero Moral, R. \& Del Río, V. (2006). Octavas falsas. Materiales de arte y estética, 2 (pp. 111-142). Salamanca: LusoEspañola de Ediciones.

Fischer-Lichte, E. (2011). Estética de lo performativo. Madrid: Abada.

Foster, H. (Ed.). (1985). La posmodernidad. Barcelona: Kairós.

Foster, H. (2001). El retorno de lo real. La vanguardia a finales de siglo. Madrid: Akal.

Foucault, M. (2003). Sobre la Ilustración. Madrid: Tecnos.

Habermas, J. (1985). La modernidad, un proyecto incompleto. En Foster, H. (Ed.). La posmodernidad (pp. 19-36). Barcelona: Kairós.

Kotz, L. (2009). Texto e imagen: relectura del arte conceptual. Papel Alpha. Cuadernos de fotografía, 7, 57-89.

Jameson, F. (1991). El posmodernismo o la lógica cultural del capitalismo avanzado. Barcelona: Paidós.

Jencks, Ch. (2004). El nuevo paradigma en la arquitectura contemporánea. Valencia: Ediciones Generales de la Construcción.

Koolhaas, R. (2006). La ciudad genérica. Barcelona: Gustavo Gili.

Koolhaas, R. (2007). Espacio basura. Barcelona: Gustavo Gili.

Lyotard, J-F. (1984). La condición postmoderna. Informe sobre el saber. Madrid: Cátedra.

Lyotard, J-F. (1987). La posmodernidad (explicada a los niños). Barcelona: Gedisa.

Pérez, D. (Ed.) (2004). La certeza vulnerable. Cuerpo y fotografía en el siglo XXI. Barcelona: Gustavo Gili. 
Pérez, D. (2012). Dicho y hecho. Textos de artista y teoría del arte. Vitoria: Artium.

Pultz, J. (2003). La fotografía y el cuerpo. Madrid: Akal.

Ribalta, J. (Ed.). (2004). Efecto real. Debates posmodernos sobre fotografía. Barcelona: Gustavo Gili.

Roberts, J. (2009). Fotografía, iconofobia y las ruinas del arte conceptual. Papel Alpha. Cuadernos de fotografía, 7, 25-55.

Sarmiento, J. A. (Ed.). (2012). Música y acción. Granada: Centro José Guerrero/Diputación de Granada.

Venturi, R., Scott Brown, D. \& Izenour, S. (1978). Aprendiendo de Las Vegas. El simbolismo olvidado de la forma arquitectónica. Barcelona: Gustavo Gili.

Cómo citar: Pérez, D. (2015). "La instantánea imposible: fotografía, neovanguardia y posmodernidad en el contexto del arte crítico contemporáneo". Fotocinema. Revista científica de cine y fotografía, 10, pp. 155-187.

Disponible: http://www.revistafotocinema.com/index.php?journal=fotocinema\&page=article\&op =view\&path[]=279 